medicine can be computerized or not, do we want to computerize it? Sooner or later mankind must ask what it is going to do with all the human energy and time that the computers are beginning to release or make redundant. - I am, etc.,

W. C. WATSON

Department of Medicine and Gastrointestinal Unit, Victoria Hospital,

Ontario, Canada

\section{Child Health in a Changing Community}

SIR,-I read Professor S. D. M. Court's lecture with great interest (17 April, p. 125). It is indeed a masterly survey of the problem.

However, in his discussion of the partners in the team needed for a rising standard of child health he does not mention child health doctors in the clinical field employed by local authorities. Has he perhaps included them as paediatric specialists? With their knowledge of developmental paediatrics they are an important factor in seeing that the young handicapped child-from any cause-is able to fulfil his potential.-I am, etc.,

Muriel J. BRayshay President, Maternal and Child Health Group,
Society of Medical Officers of Health Manchester 23

\section{Health of Young People}

SIR,-Perhaps it is significant that in the same issue of the B.M.F. we have the stimulating article by Dr. Ronald Gibson "The Satchel and the Shining Morning Face" (5 June, p. 549) and the important letter by Dr. D. Hooker (5 June, p. 585) on abortions and legal and medical ethics. Could it be that at last the B.M.A. is becoming concerned about the behaviour of young people? There has always been interest in antenatal care, infant welfare, school health service, and care of young people at work. Can we at last turn our attentions to the effect on the health of young people by the increasing trivialization and commercialization of sex? If health education is to mean anything to the young it must provide the sort of information which can be understood. This must be scientific and strictly accurate. The recent report on the dangers of smoking is a good example.

The medical profession should be in the forefront of any campaign to raise the health of the nation. In the near future there will be an opportunity for those concerned about these problems to show their interest by action.-I am, etc.,

London N.W.6

STANLEy ElLison

\section{Failure to Continue Education}

SIR,-In an analysis ${ }^{1}$ of the response of 99 general practitioners to a programme of continuing education we found that 64 of them attended three or more local sessions during the 13 months of the study and 35 attended fewer than three. We thought we should try to find out how we could make our programme more attractive.

Thirty-four of the 35 are still in practice, and each was asked to complete a question- naire designed to find out what he thought about our postgraduate programme and what sort of meeting he would prefer. Thirty-two of the 34 did so. Those who had attended meetings elsewhere were asked their reasons for doing so, and what courses they had attended. Information about years since graduation and number in partnership was available for the 34 doctors (group 1) and for the 64 (group 2) who had attended three or more sessions.

The Figure shows the distribution of the 34 doctors in terms of years since graduation (hatched) set against that of the whole group. The figures in the hatched areas give the percentage of the total number of doctors in each column who attended fewer than three sessions. Sixteen $(47 \%)$ doctors in group 1 worked single-handed or in twoman practices compared with 20 (31\%) doctors in group 2, and $16(47 \%)$ in group 1 lived more than five miles $(8 \mathrm{~km})$ from the postgraduate centre compared with 23 $\left(36^{\circ} \%\right.$ ) in group 2 . The reason given for poor attendance by 15 was that the time was unsuitable. Most general practitioners living more than five miles $(8 \mathrm{~km})$ from the centre found lunch-time meetings difficult. Five stated that the subjects were sometimes irrelevant to general practice, and several commented that they were hospital orientated. Of the $18(56 \%)$ who attended approved meetings elsewhere 11 chose general subjects, five cardiology, four obstetrics, four psychiatry, three family planning, three management, and one each diabetes, forensic medicine, medical hypnosis, paediatrics, rheumatology, teaching, and the social aspects of general practice. Some said they attended meetings elsewhere to meet

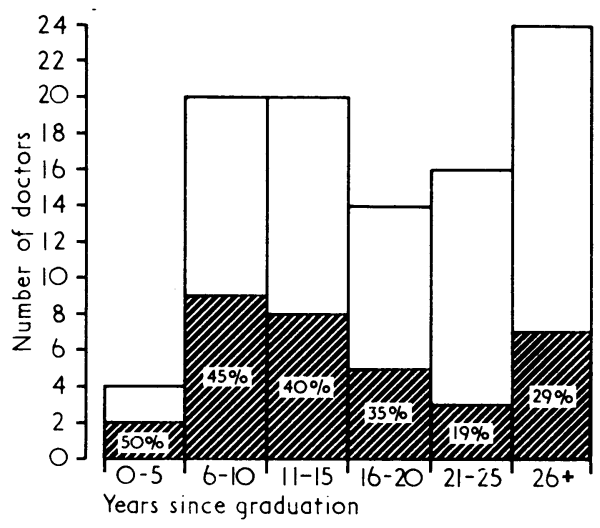

different people with different ideas. Seven held clinical posts in geriatrics, two in psychiatry, and one in anaesthetics. Of the 14 doctors in group 1 who did not attend meetings elsewhere eight ranked formal lectures first in their order of preference of type of meetings.

Contrary to our expectations the number of general practitioners attending more than three sessions increased with age, and this probably reflects the financial incentive inherent in seniority awards, which are payable only after 15 years. If meetings provide opportunities for learning it is no less important to offer incentives to recently qualified doctors, because it is easier to keep abreast of knowledge than to regain lost ground. Despite preference expressed for formal lectures we think they are of limited educational value. Meetings which encourage previous study and participation have been popular, ${ }^{1}$ and we are unwilling to change our policy. Some factors are beyond our control, but we shall try to encourage meetings at the periphery for those who find it difficult to come to our main centre and to promote as wide a variety of meetings as possible. We think incentives, financial or otherwise, might encourage younger doctors to attend. There will always be some who do not wish to come to meetings, but the onus is on the organizers to attract as many as possible.-We are, etc.,

J. T. CORBETT

P. G. DalgLeish

C. P. ElliotT-BinNS

T. A. RICHARDS E. D. SEVER

J. P. TOBY

Cripps Postgraduate Medical Centre,

Northampton

Sever, E. D., et al., British Medical fournal, 1971, 1 ,
164 .

\section{False Economy}

SIR,-I have received the current comparison of drug costs chart from the Department of Health and Social Security. It deals with hypnotics (ECL 106/69 Serial No. 4/71).

I accept that "It is not suggested that the above products necessarily have the same pharmacological properties." However, I also accept that five of the six products listed are the subject of ignorant or wanton abuse across the whole population spectrum and that such abuse is often of iatrogenic aetiology.

Unfortunately, the one compound which, so far, has not been implicated in this way is revealed as the most expensive.

In view of the current addiction problems I think that this chart-which implies and suggests preference for barbiturates-should have been withdrawn from the series. It will not alter my desire to wean my patients off the barbiturates or methaqualone, and possibly to substitute with nitrazepam. I hope that others will not find themselves feeling guilty at prescribing the safest hypnotic.-I am, etc.,

London N.9

Christopher J. DAY

\section{Coroner's Power to Commit for Trial}

SIR,-It is unfortunate that your legal correspondent, in discussing the coroner's power to commit for trial (26 June, p. 781), should misrepresent both the sequence of events which led to Ian Spencer's committal and also the meaning of my own remarks on this subject to which he refers. He clearly does not understand the normal procedure in these cases and has failed to appreciate the coroner's dilemma.

The position is as follows. If the Director of Public Prosecutions does not wish to proceed against a suspect in a case of homicide he writes to the police authority concerned to that effect and asks to be informed if any further evidence is revealed at the inquest. The case has then to be brought to inquest, and if it appears to the coroner that the death has been brought about by murder, manslaughter, or infanticide he is obliged to empanel a jury (Coroners' Amendment Act, 1926 Section 13 ss. 2). If after hearing the evidence the jury decide that there is a prima facie case of some form of homicide they must say so and if they feel that there is prima facie evidence 